\title{
Soil-Induced Increased Fertilization and Hatching of Carps
}

\author{
NR Chattopadhyay* \\ Visiting Research Professor, Department of Biotechnology \& Zoology, India
}

*Corresponding author: NR Chattopadhyay, Visiting Research Professor, Department of Biotechnology, Department of Zoology, Rono Hills, Doimukh, Itanagar 791112, India

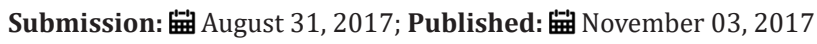

\section{Perspective}

During extensive field study, to cover the bundh breeding program at certain districts of West Bengal, India, we came across with a unique traditional and innovative technology for increasing fertilization and hatching rate of carp eggs in captivity. Bund breeding is an age old practice of some kind of sympathetic breeding technology [1-4], by utilizing the undulating terrain and vast catchment area, for quality seed production in captivity [5]. This practice was in vogue before introduction of induced breeding technique in West Bengal and was the main source of quality supply to cultivators except natural source [6-8].

Recently this technique is rejuvenated again when a question raised regarding qualitativeness of hatchery raised seeds. During review of the breeding program we noticed that the fish breeders, engaged in raising seeds through bundhs are using a particular soil (collected 8 feet below the ground which are light yellowish in colour) available at the vicinity of said breeding area (Figure1). The fish breeders are using this soil since long, with different application procedure, both at breeding and hatching bundh (specialized pond), for increasing fertilization and hatching. Besides being an enhancer of fertilization and hatching rate, the soil by way of removing the adhesive glue, can increase the fertilization rate of fishes which lay adhesive eggs such as Cyprinus carpio [9].

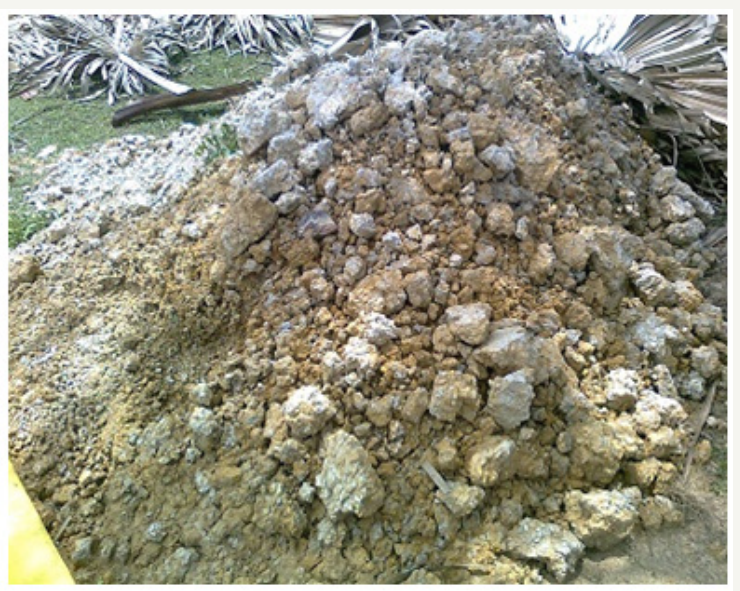

Figure 1: Characteristic soil of Bankura district of West Bengal, India.
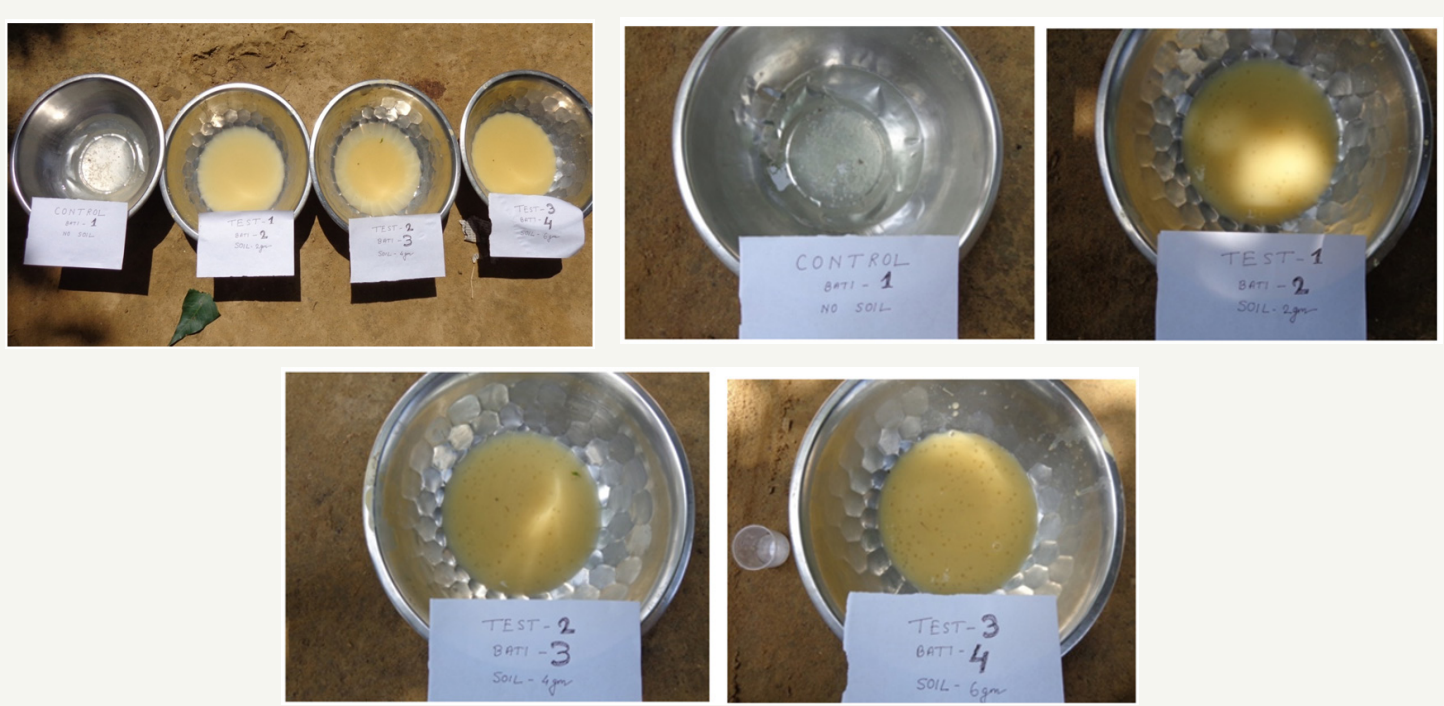

Figure 2: (B1, B2, B3 \& B4) Experimental arrangement for fertilization \& hatching percentage test. 
To evaluate the efficiency of the soil [10], an experiment was designed by using 4 nos. of steel bowl at the site of bundh breeding (Figure 2). Different doses of soil were used in four separate steel bowl considering Labeo rohita as test fish. Each pot possesses a diameter 15 inches at top, height of 8 inches with a water holding capacity of 2 litres. The bowls were numbered as B1, B2, B3 and B4. To start with each were filled with 2 litres of water and left for two days. After two days in each bowl, except bowl no. 1 (which was maintained as control), was added with the soil to be tested. Generally 2, 4 and $6 \mathrm{gm}$. Soil was added as base material in bowl no. 2, 3 and 4 respectively. The added soil was allowed to settle for 2 days and after that each bowl was stocked with $10 \mathrm{ml}$ fertilized eggs of Labeo rohita except control one. The experiment started at $10.00 \mathrm{am}$ and reviewed till hatching. From the result, hatching time and percentage were calculated as mentioned in Table 1. In Table 2 some criteria related induction of fish, spawning, hatching along with $\mathrm{pH}$ and temperature (both air and water) are depicted. The experiments were conducted at field condition and as we know temperature and $\mathrm{pH}$ play in crucial role in both spawning, fertilization and hatching so to correlate the both with overall breeding, these physical parameter were recorded. The recorded data indicate that available temperature was congenial for the said purpose. Other criteria which includes spawning, spawning time, hatching time corresponds the recommended data. The duration of the experiment means starting from injection to completion of hatching, it took on an average of 12 hours.

Table 1: Experiment for hatching rate on rohu fish (Labeo rohita), Place-Panchmura, Date-7.06.14, Time-10.00 am.

\begin{tabular}{|c|c|c|c|c|c|}
\hline & $\begin{array}{l}\text { Experimental } \\
\text { Set-Up }\end{array}$ & $\begin{array}{c}\text { B1 } \\
\text { (Control) }\end{array}$ & $\begin{array}{c}\text { B2 } \\
\text { (2gm } \\
\text { Soil) }\end{array}$ & $\begin{array}{l}\text { B3 (4g } \\
\text { Soil) }\end{array}$ & $\begin{array}{l}\text { B4 (6gm } \\
\text { Soil) }\end{array}$ \\
\hline 1 & $\begin{array}{l}\text { Amount of } \\
\text { fertilized egg } \\
\text { inoculated } \\
\text { in } \mathrm{ml}\end{array}$ & $10 \mathrm{ml}$ & $10 \mathrm{ml}$ & $10 \mathrm{ml}$ & $10 \mathrm{ml}$ \\
\hline 2 & $\begin{array}{l}\text { No. of eggs } \\
\text { available for } \\
\text { test }\end{array}$ & 310 & 298 & 310 & 302 \\
\hline 3 & $\begin{array}{l}\text { No. of eggs } \\
\text { fertilized }\end{array}$ & 133 & 199 & 211 & 215 \\
\hline 4 & $\begin{array}{c}\text { No. of } \\
\text { unfertilized } \\
\text { eggs }\end{array}$ & 177 & 99 & 99 & 87 \\
\hline 5 & $\begin{array}{l}\text { Fertilization } \\
\text { percentage }\end{array}$ & 42.91 & 66.78 & 68.06 & 71.19 \\
\hline 6 & $\begin{array}{l}\text { Hatching } \\
\text { Percentage }\end{array}$ & 39.21 & 72.12 & 73.09 & 78.08 \\
\hline 7 & $\begin{array}{l}\text { No. of spawn } \\
\text { at hatching }\end{array}$ & 36 & 269 & 266 & 261 \\
\hline 8 & $\begin{array}{c}\text { Time taken for } \\
\text { hatching }\end{array}$ & $3 \frac{1}{2} 2 \mathrm{hrs}$ & $4 \mathrm{hrs}$ & $4 \frac{1}{2} / 2 \mathrm{hrs}$ & $5 \mathrm{hrs}$ \\
\hline
\end{tabular}

Table 2: Observation on different time for hatching and breeding of experiment 3.

\begin{tabular}{|c|c|}
\hline Air Temperature & $30{ }^{\circ} \mathrm{C}$ \\
\hline Water Temperature & $24{ }^{\circ} \mathrm{C}$ \\
\hline $\mathrm{pH}$ & 6 \\
\hline No. of fish injected for spawning & $\begin{array}{c}30 \text { out of } 200(100 \text { male }+100 \\
\text { female })\end{array}$ \\
\hline Injection time & 06.06 .14 at 2.30 p.m. \\
\hline Release of egg and spawn started & 06.06 .14 at 7.30 p.m. \\
\hline Egg \& spawn release completed & 06.06 .14 at 11.30 p.m. \\
\hline Collection of egg started & 07.06 .14 at 8.00 a.m. \\
\hline Egg transfer to hatching pond & 07.06 .14 at 9.00 a.m. \\
\hline Hatching start & 07.06 .14 at 10.00 a.m. \\
\hline Hatching end & $\begin{array}{c}07.06 .14 \text { between } 1.30 \text { p.m. to } 3.00 \\
\text { p.m. }\end{array}$ \\
\hline
\end{tabular}

In Table 1 along with other relevant criteria fertilization and hatching rate are noted mainly to evaluate the role of soil in enhancing the said phenomenon. As per Table 1,10ml of fertilized eggs were inoculated in each bowl but the number of eggs varied as per availability. Out of the total initial eggs (298-310), the fertilized and non-fertilized eggs were segregated according to number. Based on the number of fertilized eggs fertilization percentage (ranged from 42.91-71.19) was derived respectively for each separate bowl. Maximum fertilization was notice in bowl no. 4 (71.19\%) and in no. $3(68.06 \%)$. In bowl no. 2 , the rate was $66.78 \%$ while in control it was $42.91 \%$. Similarly hatching rate was maximum at bowl no.4 (78.80\%), followed by bowl no. 3 (73.09\%), no. 2 (72,12\%) and in control (39.21). Again soil based eggs took more time to hatch than that of the eggs maintained in control pot.

The experimental data, as envisaged from the Table no. 3, indicate a highly positive significant role of the soil under study, in enhancing the fertilization and hatching rate of eggs of Labeo rohita. One way anova test of the experimental data indicate highly significant value in respect of fertilization and hatching ( $\mathrm{P}=0.003219)$.

Results of percentage wise elemental composition indicate oxygen was highest (50.38\%), followed by silicon $(22.52 \%)$, iron $(15.21 \%)$, aluminium $(5.5 \%)$ potassium $(4.60 \%)$ and titanium (2.05\%) (Table 3). The soil was completely devoid of carbon, chloride and calcium. One of the major elemental compositions of the soil under consideration is the presence of silicon in the form of silicon dioxide (SiO2). Besides acting as an abiotic component, it also influences the behaviour, breeding and spawning of psamophilic (sand loving) fishes and also acts as an aquifer by storing a large amount of water. With metallic ion it forms silicate salts like potassium and sodium silicate. In silicate form it not only acts as a ready source of oxygen but turns the water towards alkaline side. From the experiment and subsequent elemental analysis, we assume that the particular soil, create a favourable breeding, fertilization and hatching environment in aquatic system. Further study is needed to unveil the actual role of constituent element in stimulating the overall breeding behaviour of freshwater fishes [11-13]. 
Table 3: Observation on percentage composition, different element of experimental soil.

\begin{tabular}{|c|c|}
\hline Element & Percentage Composition \\
\hline Oxygen & 50.38 \\
\hline Silicon & 22.52 \\
\hline Aluminium & 5.57 \\
\hline Potassium & 4.6 \\
\hline Titanium & 2.05 \\
\hline Iron & 15.21 \\
\hline Carbon & 0 \\
\hline Chloride & 0 \\
\hline Calcium & 0 \\
\hline
\end{tabular}

\section{References}

1. Dhote AK (1992) Fish Breeding, NCERT, pp. 33-43.

2. Hickling CF (1971) Fish Culture. Faber and Faber. London, England, pp. 225.

3. Jhingran VJ (1991) Fish and Fisheries of India. pp. 276.

4. Khanna SS (1992) An Introduction to Fishes. pp. 506-512.

5. Ghorai PP, Chattopadhyay NR, Dey SK (2016) Innovation in bundh breeding unveil a new avenues for quality seed production in captivity.
International Journal of Agricultural Extension and Rural Development Studies 3(1): 37-45.

6. Chattopadhyay NR, Ghorai PP, De SK (2013) Bundh breedingrejuvenation of a novel technology for quality seed production by the fish seed producers of bankura district in west Bengal, India. International Journal of Current Science 9: 123-132.

7. Basavaraja N (2007) Freshwater fish seed Resources in India, pp. 267327.

8. Chattopadhyay GN (1998) Chemical Analysis of Fish Pond Soil and Water. pp 72.

9. Chattopadhyay NR (2014) Simple Soil Solution Removes Egg Adhesive to Enhance Carp Seed Production, global aquaculture advocate.

10. Banerjea SM (1967) Water quality and soil condition of fish ponds in some states of India in relation to fish production. Indian J Fish 14(1-2) 115-144.

11. Khanna SS (1978) An introduction to fish. Centra Book Depot, India, p. 485.

12. Mandal LN, Chattopadhyay GN (1992) Nutrient management in aquaculture. In: Tandon HLS (Ed.), Non-Traditional Sectors in Fertilizer Use. FDCO, New Delhi, India, pp. 1e17.

13. Mandal LN (1992) Nutrient Management in Aquaculture. In: Chattopadhyay GN (Ed.), Journal of the Indian Society of Soil Science 17(1): 51-57. 